\title{
The effect of conjugated linoleic acid isomers, selenite and selenized yeast supplemented to the diet on the fatty acid profile in the pancreas of rats*
}

\author{
M. Czauderna ${ }^{1}$, J. Kowalczyk and K.A. Krajewska
}

\author{
The Kielanowski Institute of Animal Physiology and Nutrition, Polish Academy of Sciences \\ 05-110 Jabłonna, Poland
}

(Received 20 May 2010; revised version 16 June 2010; accepted 16 August 2010)

\begin{abstract}
The influence of dietary conjugated linoleic acid (CLA) isomers (CLAmix) and/or Se as $\mathrm{Na}_{2} \mathrm{SeO}_{3}(\mathrm{SeIV})$ or selenized yeast (SeY) on the relative body weight gain (RBWG) of rats, pancreas weight, concentrations of CLA isomers and of other fatty acids (FA) in the pancreas were studied. For 6 weeks, female rats Wistar (aged 8 weeks) were fed ad libitum the Labofeed H diet enriched in $1.5 \%$ CLAmix, $0.2 \mathrm{ppm} \mathrm{Se}\left({ }_{\mathrm{L}} \mathrm{Se}\right), 0.5 \mathrm{ppm} \mathrm{Se}\left({ }_{H} \mathrm{Se}\right)$ as SeIV (i.e. ${ }_{\mathrm{L}} \mathrm{SeIV}$ or ${ }_{\mathrm{H}} \mathrm{SeIV}$, respectively), or $\mathrm{SeY}$ (i.e. ${ }_{\mathrm{L}} \mathrm{SeY}$ or ${ }_{\mathrm{H}} \mathrm{SeY}$, respectively). Each group contained eight rats. The results documented that dietary ${ }_{\mathrm{L}} \mathrm{SeIV}$ and CLAmix most effectively increased the RBWG of rats and feed conversion efficiency, while the diet with ${ }_{H}$ SeIV most efficiently increased pancreas weight compared with the control rats. The diets enriched in CLAmix and Se as SeIV or SeY increased the sum of saturated fatty acids (SFA), the atherogenic SFA, A-SFA index, thrombogenic SFA (T-SFA), and the T-SFA index in the pancreas of rats compared with the control group. The diets containing CLAmix and $\mathrm{Se}$ as SeIV or SeY stimulated the accumulation of cis9trans11CLA, trans10cis12CLA, as well as the sum of all CLA isomers in the pancreas compared with rats fed the diet enriched in CLAmix. These diets increased the concentration of n- 6 polyunsaturated FA (n-6 PUFA) and decreased the level of long-chain n-6 PUFA (Ln-6 PUFA) in the pancreas compared with the control rats and rats fed the diets with SeIV or SeY. The diets containing CLAmix and Se (as SeIV or SeY) increased the concentration of n-3 PUFA and Ln-3 PUFA in the pancreas compared with the control rats. Our study findings documenting that dietary Se and/or CLAmix and Se (as SeIV or SeY) considerably increased the concentration of PUFA, especially n-3 PUFA, improved the n-6 PUFA/n-3 PUFA ratio in the pancreas are valuable information for scientists carrying out research to improve animal and human health.
\end{abstract}

\footnotetext{
* Supported in part by the Ministry for Science and Information, Grant No. N N311 336433

${ }^{1}$ Corresponding author: e-mail: m.czauderna@ifzz.pan.pl
} 
KEY WORDS: rats, pancreas, selenite, selenized yeast, CLA isomers, fatty acids, desaturases

\section{INTRODUCTION}

Selenium (Se) is an essential trace element for humans and animals. Se is a component of a number of important Se-enzymes required for such functions as anticancer defence, reduction of inflammation, DNA synthesis, fertility, reproduction and thyroid hormone production (e.g., thyroid hormone deiodinase families or thioredoxin reductase) (Rayman, 2004; Suzuki, 2005; Boosalis, 2008; Juniper et al., 2008; Navarro-Alarcon and Cabrera-Vique, 2008). Moreover, previous investigations have shown that feeding diets enriched in selenium (Se) as selenite (SeIV), selenate (SeVI), or selenized yeast (SeY) to animals results in effective induction of antioxidant enzymes, indicating that the animal converts the dietary form of Se to Se-cysteine (Se-Cys), which is an essential amino acid for the synthesis of these Se-proteins (e.g., glutathione peroxidise family) (Whanger, 2004; Navarro-Alarcon and Cabrera-Vique, 2008; Yu et al., 2008). Therefore, these protective effects of dietary Se on unsaturated fatty acids (UFA), especially conjugated linoleic acid (CLA) isomers, in tissues and organs of mammals may also be plausible. Indeed, in our previous studies we found that dietary $\mathrm{Se}$ (as $\mathrm{SeIV}, \mathrm{SeVI}$ or SeY) and/or CLA isomers influence the concentration of fattyand amino acids in the liver, femoral muscles, heart, kidneys or spleen of rats (Czauderna et al., 2004, 2007a, 2009a,b; Korniluk et al., 2007). Considering the above, we hypothesized that a diet enriched in CLA isomers with or without selenite (SeIV) or selenized yeast (SeY) affected the concentration of fatty acids in the pancreas of rats. The pancreas is an important dual-function gland, having features of both endocrine and exorcine glands. The part of the pancreas with endocrine function is made up of cell clusters called islets of Langerhans. In contrast to the endocrine pancreas, which secretes hormones into the blood, the exocrine pancreas synthesizes digestive enzymes and pancreatic juice, and secretes them into the small intestine through a system of exocrine ducts in response to the small-intestine hormones, secretin and cholecystokinin. Digestive enzymes include trypsin,chymotrypsin, pancreatic lipase, and pancreatic amylase, and are produced and secreted by acinar cells of the exocrine pancreas.

In our recent studies we found that the addition of $\mathrm{SeVI}$ or $\mathrm{SeY}$ to a diet enriched in CLA isomers affected the deposition of CLA isomers in tissues and selected organs of rats (Czauderna et al., 2004, 2007a, 2009a,b; Korniluk et al., 2007). Therefore, the objective of our study was to investigate the influence of different chemical forms of Se added to a diet on the deposition of CLA isomers and other fatty acids (FA) in the rat pancreas, which has features of endocrine and exorcine glands. 


\section{MATRERIAL AND METHODS}

Animals, housing, diets, experimental design and sampling

The experiment was conducted with 80 female rats (Wistar, Hsd Brl Han: WIST), aged 8 weeks with an initial body weight of $195.7 \pm 0.8 \mathrm{~g}$. The animals were housed and handled in accordance with protocols approved by the Local Animal Care and Use Committee (The Agricultural University of Warsaw, Poland). The rats were housed individually in metabolic cages at a temperature of $22 \pm 1^{\circ} \mathrm{C}$ with a $12 \mathrm{~h}$ light-dark cycle and relative humidity of $50-60 \%$. Each group comprised eight rats. The rats were fed the commercial diet for laboratory rats and mice (the trade name Labofeed $\mathrm{H}$ diet). This diet was purchased from the Feeds and Concentrates Production Plant in Kcynia, MORAWSKI Co., Poland (www.wpmorawski.com.pl/Labofeed/labofeed). The Labofeed $\mathrm{H}$ diet has been produced according to ISO 9001 Standards since 1998. For our studies, this commercial diet containing $0.13 \mathrm{ppm}$ Se (the natural content of Se) was enriched in only $0.2 \mathrm{ppm}$ Se as selenite (Table 1). Therefore, the total concentration of Se in this commercial rat diet was $0.33 \mathrm{ppm}$ Se.

During the one-week preliminary period the rats were fed the standard Labofeed $\mathrm{H}$ diet offered at a sub-maintenance level to reduce body fat (Table 1). Next, for 6 weeks the rats were fed ad libitum the experimental diets supplemented with $1.5 \%$ CLA isomer mixture (CLAmix), $0.2 \mathrm{ppm} \mathrm{Se}$ or $0.5 \mathrm{ppm} \mathrm{Se}$ as $\mathrm{Na}_{2} \mathrm{SeO}_{3}$ (i.e. ${ }_{\mathrm{L}} \mathrm{SeIV}$ or ${ }_{\mathrm{H}} \mathrm{SeIV}$, respectively) and $\mathrm{SeY}$ (i.e. ${ }_{\mathrm{L}} \mathrm{SeY}$ or ${ }_{\mathrm{H}} \mathrm{SeY}$, respectively) (Table 1). Feed intake and body weight of rats were measured weekly. At the end of the six-week experiment the rats were euthanized by $\mathrm{CO}_{2}$. The pancreases were removed, weighed, and frozen until analysed. All tissue samples from each rat were analysed individually. The concentrations of all fatty acids (FA) were calculated based on freeze-dried pancreas samples.

\section{Reagents}

All chemicals were analytical grade and organic solvents were of HPLC grade. Dichloromethane (DCM), KOH, $\mathrm{NaOH}, \mathrm{Na}_{2} \mathrm{SO}_{4}$ and conc. $\mathrm{HCl}$ were purchased from POCH (Gliwice, Poland). Acetonitrile, methanol, and n-heptane (99\%, GC) were supplied by Lab-Scan (Ireland), while the CLA isomer mixture $(2.1 \% t t$ CLA, $7.1 \%$ c11t13CLA, 40.8\% c9t11CLA, 41.3\% t10c12CLA, $6.7 \% c 8 t 10 \mathrm{CLA}$ and $2.0 \% c c$ CLA), by the Industrial Chemistry Research Institute (Warsaw, Poland). The concentration ratio $\left(\mathrm{R}_{c \text { t tIICLA } t / 10 c 12 \mathrm{CLA}}\right)$ of $c 9 t 11$ CLA to $t 10 c 12$ CLA in the dietary CLA isomer mixture was 0.988 . Fatty 


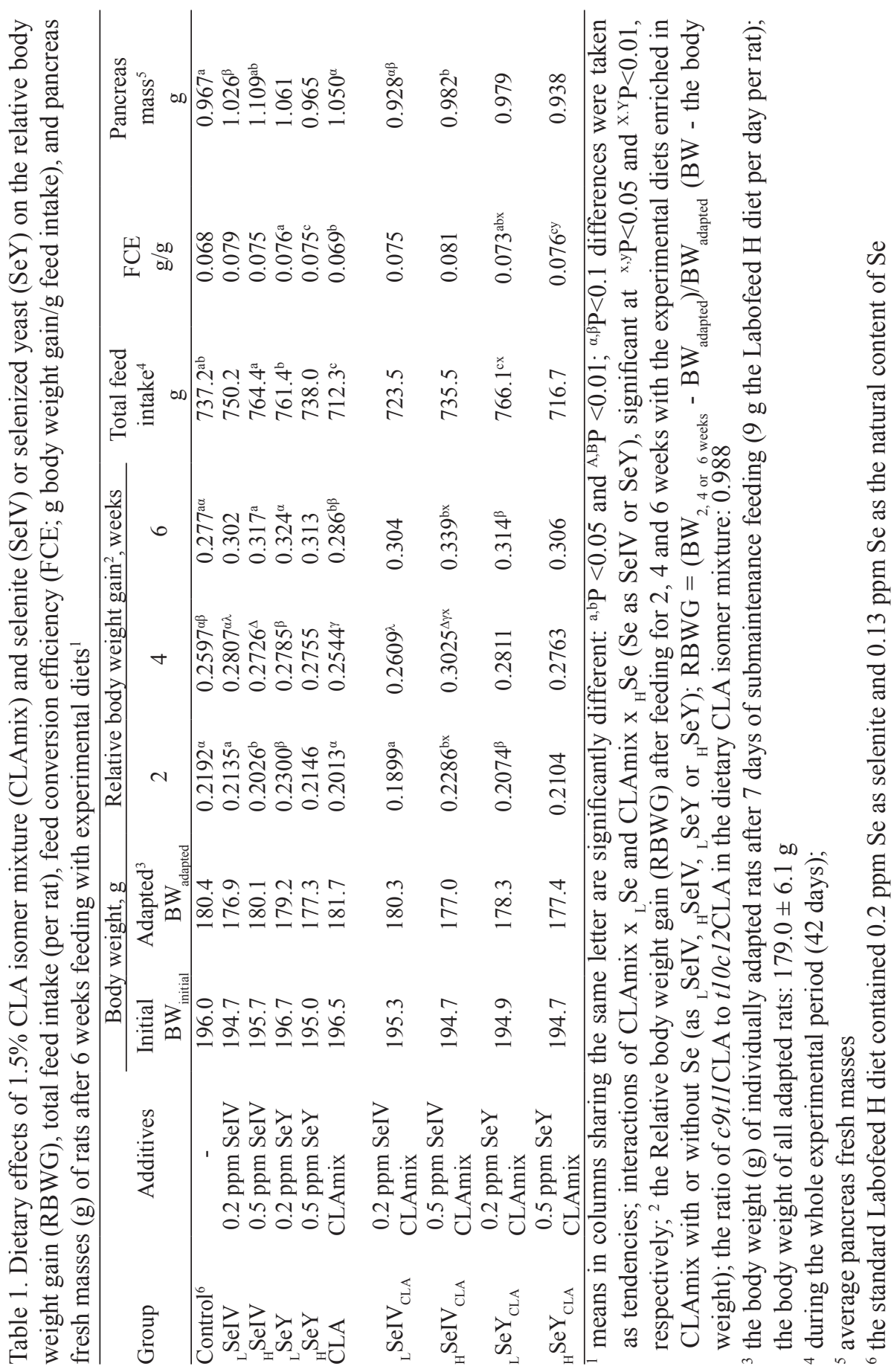


acid methyl ester (FAME) standards, sodium selenite $\left(\mathrm{Na}_{2} \mathrm{SeO}_{3}\right)$ and $50 \% \mathrm{BF}_{3}$ in methanol were purchased from Supelco and Sigma (USA).

The selenized yeast (Se-Saccharomyces cerevisiae) was donated by Sel-Plex (a non-commercial yeast sample; Alltech In., USA). About $83 \%$ of the total Se concentration of selenized yeast $(\mathrm{SeY})$ represents $\mathrm{Se}$ in the form of Se-methionine (Se-Met) incorporated into proteins of Saccharomyces cerevisiae (Rayman, 2004; Weiss and Hogan, 2005).

Water used for the preparation of mobile phases and chemical reagents was prepared using an Elix ${ }^{\mathrm{TM}}$ water purification system (Millipore). The mobile phases were filtered through a $0.45 \mu \mathrm{m}$ membrane filter (Millipore).

\section{Analytical methods}

The methods of alkaline hydrolysis and base- and acid-catalysed methylation of fatty acids (i.e. the derivatization) were as previously described (Czauderna et al., 2009a). The methylated CLA isomers (CLA-ME) were determined using silver ion liquid chromatography with photodiode array detection $\left(\mathrm{Ag}^{+}\right.$-HPLCDAD) according to Czauderna et al. (2007b).

The concentrations of methylated FA (i.e. FAME and CLA-ME) in pancreases were calculated based on freeze-dried pancreas samples.

\section{Analytical equipment}

The analyses of methylated fatty acids (FAME) were performed on a SHIMADZU GC-MS-QP2010 Plus EI equipped with a BPX70 fused silica capillary column $(120 \mathrm{~m} \times 0.25 \mathrm{~mm}$ i.d. $\times 0.25 \mu \mathrm{m}$ film thickness; SHIM-POL, a quadrupole mass selective (MS) detector (Model 5973N) and an injection port. Helium as the carrier gas operated at a constant pressure $(223.4 \mathrm{kPa})$ and flow rate of $1 \mathrm{ml} / \mathrm{min}$. Injector and MS detector temperatures were maintained at 200 and $240^{\circ} \mathrm{C}$, respectively. The total FAME profile in a one $\mu \mathrm{l}$ sample at the split ratio of 10:1 was determined using the column temperature gradient programme, which was as previously described (Czauderna et al., 2009a).

FAME identification was validated based on electron impact ionization spectra of FAME and compared with authentic FAMS standards and the NIST (wyjaśnić skrót!) 2007 reference mass spectra library.

Methylated CLA isomers (CLA-ME) were determined using a Waters 625 LC system that included a controller for gradient elution and two pumps (Waters Model 515). The apparatus consisted of a Waters 712 WISP autosampler, two ion-exchange columns loaded with silver ions $(250 \times 4.6 \mathrm{~mm}$ Chrompack ChromSper $5 \mu \mathrm{m}$ Lipids, the Netherlands) and a Waters 996 photodiode array detector (Czauderna et al., 2007b). 


\section{Statistical analyses}

Results are presented as means \pm SD of 8 individually analysed samples of rat pancreases. The one-factorial statistical analyses of the effects of SeY or the CLAmix in the experimental diets were conducted using the non-parametric Mann-Whitney U test for comparing independent experimental groups. Statistical analyses of the interactions between CLAmix and ${ }_{\mathrm{L}} \mathrm{Se}\left({ }_{\mathrm{L}} \mathrm{Se}_{\mathrm{CLA}}\right)$ and CLAmix and ${ }_{\mathrm{H}} \mathrm{Se}\left({ }_{\mathrm{H}} \mathrm{Se}_{\mathrm{CLA}}\right)$ were performed using two-factorial ANOVA analyses. Differences were considered significant at the $\mathrm{P}<0.05\left(^{*}\right)$ and $\mathrm{P}<0.01(* *)$ levels, while at $\mathrm{P}<0.1\left(^{\alpha}\right)$ differences were labeled tendencies. Statistical analyses were performed using the Statistica v. 6 software package (Statistica, 2002; www.statsoft.pl).

\section{RESULTS AND DISUSSION}

The influence of dietary CLA isomers and Se on rat body weight gain and pancreas weight. Our results regarding the concentration of additives in the diets as well as the influence of the examined diets on the growth performance of rats are summarized in Table 1. As expected, no macroscopic lesions or pathological changes were found in the pancreas or other internal organs and tissues of rats fed the diets enriched in CLA isomers and/or $0.2 \mathrm{ppm}$ or $0.5 \mathrm{ppm}$ Se as SeIV or SeY. Thus, the current results are consistent with our recent studies (Korniluk et al., 2007; Czauderna et al., 2009a,b) corroborating that only chronic feeding of Se compounds at a rate of more than $5 \mathrm{ppm}$ Se can be teratogenic and hepatotoxic in animals and humans (Tapiero et al., 2003).

It was found that supplementation of the diet with CLAmix tended to decrease $(\mathrm{P}=0.07)$ the relative body weight gain $(\mathrm{RBWG})$ of rats compared with the control rats during the two weeks of the experiment (Table 1). On the other hand, the effects of dietary 1.5\% CLAmix on body weight gain were rather small after 6 weeks of the experimental period. It seems reasonable to assume that dietary CLAmix is responsible, especially after 2 weeks of the experiment, for the reduction of fat, whereas these isomers in the diet after 4 weeks of the experimental period stimulated the accumulation of water (Javadi et al., 2007). Indeed, a negative correlation between body fat and body water content is observed in rodents fed the diet enriched in CLA isomers (Javadi et al., 2007).

Interestingly, the addition of $0.2 \mathrm{ppm}$ Se as SeIV to the diet containing CLAmix exhibited a stronger influence on diminishing the RBWG of rats compared with the control rats, and especially, on the body gain of rats fed the diet with ${ }_{\mathrm{L}} \mathrm{SeIV}$ $(\mathrm{P}<0.05)$ during the two weeks of the experiment. Our results also documented that the diet with the higher concentration of SeY (organic Se), regardless of 
the presence of CLAmix, had an inhibitory effect on body protein synthesis (Navarro-Alarcon and Cabrera-Vique, 2008) compared with the diets containing the lower level of SeY. On the other hand, the diet with the higher content of SeIV (inorganic Se), especially containing CLAmix, was not associated with the detrimental effect of Se accumulated in rat bodies. The explanation for these effects is that the accumulation of Se is lower in bodies of rats fed the diet with inorganic Se in comparison with dietary organic Se (Czauderna et al., 2007a, 2009a,b; Niedźwiedzka et al., 2007). Our results documented that dietary ${ }_{L}$ SeIV and CLAmix is the most beneficial for rats. This conclusion is supported by the higher values of RBWG of rats and feed conversion efficiency (FCE) (Table 1). Similarly, the diet containing ${ }_{\mathrm{H}} \mathrm{SeIV},{ }_{\mathrm{L}} \mathrm{SeY}$ or ${ }_{\mathrm{H}} \mathrm{SeY}$, irrespective of the presence of CLAmix, numerically increased FCE values compared with the control rats. Moreover, in our studies, the diet enriched to a higher concentration of SeIV $\left({ }_{H} \mathrm{SeIV}\right)$ or the lower concentration of $\mathrm{SeY}\left({ }_{L} \mathrm{SeY}\right)$, effectively increased the RBWG of rats in comparison with the control rats, especially after 6 weeks of the experiment. Furthermore, the diet containing the lower concentration of SeY was more efficient than the diet with the higher concentration of SeIV in increasing RBWG. These results might be associated with the more efficient retention of organic Se in tissues of animals compared with dietary inorganic Se (Han et al., 2009). On the other hand, the higher concentration of $\mathrm{SeY}\left({ }_{\mathrm{H}} \mathrm{SeY}\right)$ in the diet more efficiently reduced rat growth (due to upregulation of anabolic processes in rats) compared with dietary ${ }_{\mathrm{L}} \mathrm{SeY}$. Indeed, our recent papers documented that dietary $\mathrm{Se}$ as $\mathrm{SeY}$ was accompanied by higher retention of Se in rat tissues in comparison with selenite or selenate (Czauderna et al., 2004, 2007a, 2009a,b; Niedźwiedzka et al., 2007). We suggest that the higher retention of Se in the rats fed the diet with ${ }_{H} \mathrm{SeY}$ upregulated anabolic processes in rats.

On the other hand, the addition of $1.5 \%$ CLAmix to the diet decreased total feed intake and FCE. Our results are supported by several other studies, which have indicated that CLA isomer $t 10 c 12$ in particular, due to its geometric and positional structure, is the most potent CLA isomer in terms of antiobesity activity, thus, the one which most efficiently reduces feed intake, body weight gain, as well as increases energy expenditure (Alasnier et al., 2002; Belury, 2002; Czauderna et al., 2007a; 2009a,b; Niedźwiedzka et al., 2007).

As can be seen from the data in Table 1, the diet containing ${ }_{L}$ SeIV, ${ }_{H} S e I V,{ }_{L} S e Y$ or CLAmix numerically or statistically increased pancreas weight compared with the control group. Thus, it can be concluded that less available inorganic Se (i.e. dietary ${ }_{\mathrm{L}} \mathrm{SeIV}$ or ${ }_{\mathrm{H}} \mathrm{SeIV}$ ) and lower amounts of dietary SeY stimulated pancreas growth. On the other hand, the higher amount of dietary organic $\mathrm{Se}\left({ }_{\mathrm{H}} \mathrm{SeY}\right)$ had a detrimental effect on pancreas growth in comparison with rats fed the diets enriched in ${ }_{\mathrm{L}} \mathrm{SeIV},{ }_{\mathrm{H}} \mathrm{SeIV}$ or ${ }_{\mathrm{L}} \mathrm{SeY}$. Indeed, the higher amount of dietary organic 
Se as ${ }_{\mathrm{H}} \mathrm{SeY}$ resulted in greater deposition of Se in the pancreas and other organs compared with dietary ${ }_{H}$ SeIV or ${ }_{L}$ SeY. Thus, we suggest that the high pancreatic concentration of Se (mainly as Se-methionine) catalyses hydrosulphide oxidation (Javadi et al., 2007) which exerts an inhibitory effect on pancreas growth compared with rats fed the diets enriched in ${ }_{L} \mathrm{SeIV},{ }_{H} \mathrm{SeIV},{ }_{\mathrm{L}} \mathrm{SeY}$ or CLAmix. On the other hand, the CLAmix x Se interactions (regardless of the level and chemical form of Se) did not influence pancreas weight (Table 1).

Effect of the diets with CLAmix and Se on pancreatic contents of saturated and monounsaturated FA, and CLA isomers. One of the most prominent effects of dietary supplementation with CLAmix and Se as SeIV or SeY (regardless of the concentration of extra Se), is an increase in the sum of saturated fatty acids (SFA), atherogenic SFA (A-SFA), A-SFA index, and thrombogenic SFA (T-SFA), T-SFA index, as well as individual saturated fatty acids such as C14:0, C16:0, in the pancreas of rats compared with the control group (Tables 2 and 3). This effect on the concentration of these fatty acids might be due to the lower capacity of $\Delta 9-, \Delta 6$ - and $\Delta 5$-desaturase in the pancreas of rats fed the diet with CLAmix and Se as SeIV or SeY (Table 3). Moreover, this decrease in the capacity of these desaturases is concomitant with the decrease in the pancreatic concentration of $c 9 \mathrm{C} 18: 1$, the sum of monounsaturated fatty acids (MUFA), and with the increase in the A-SFA and T-SFA indexes.

Interestingly, the diet enriched in ${ }_{\mathrm{L}} \mathrm{SeY}$ decreased the concentration of SFA, T-SFA, as well as individual saturated fatty acids such as C14:0, C16:0 in the pancreas (Table 2). Unfortunately, this diet also resulted in a decrease in the capacity of $\Delta 9$-desaturase in this organ (Table 3). Consequently, the addition of the lower amount of $\mathrm{SeY}$ to the diet decreased the concentration of $c 9 \mathrm{C} 18: 1$, as well as MUFA in the pancreas of rats.

The diets containing CLAmix and Se as SeIV or SeY (regardless of the level of extra Se) stimulated the accumulation of $c 9 t 11 \mathrm{CLA}, t 10 c 12 \mathrm{CLA}$, as well as the sum of all assayed CLA isomers in the pancreas in comparison with rats fed the diet enriched in only CLAmix. Our studies documented that the concentration ratio of $c 9 t 11$ CLA to $t 10 c 12 \mathrm{CLA}$ in the pancreas of rats fed the diets enriched with the CLAmix was, regardless of the presence of extra Se, higher compared with the ratio $\left(\mathrm{R}_{c|t| l \mathrm{CLA} / t 10 c 12 \mathrm{CLA}}\right)$ of these isomers in the CLA isomer mixture added to the diets (i.e. 1.82-1.52 vs 0.988 ; see Tables 1 and 2). Thus, our present results are in agreement with those of Alasnier et al. (2002) and our previous study (Czauderna et al., 2007a, 2009a,b, 2010), in which t10c12CLA and t10t12CLA were also more efficiently driven through $\beta$-oxidation in the tissues of the examined animals than their 9,11 CLA-homologues. Interestingly, our studies documented that the $\mathrm{R}_{\text {cttllCLA } t 10 c \text { c } 2 \mathrm{CLA}}$ values were lower in the pancreas of rats fed the diet containing CLAmix and Se (as SeIV or SeY) compared with 


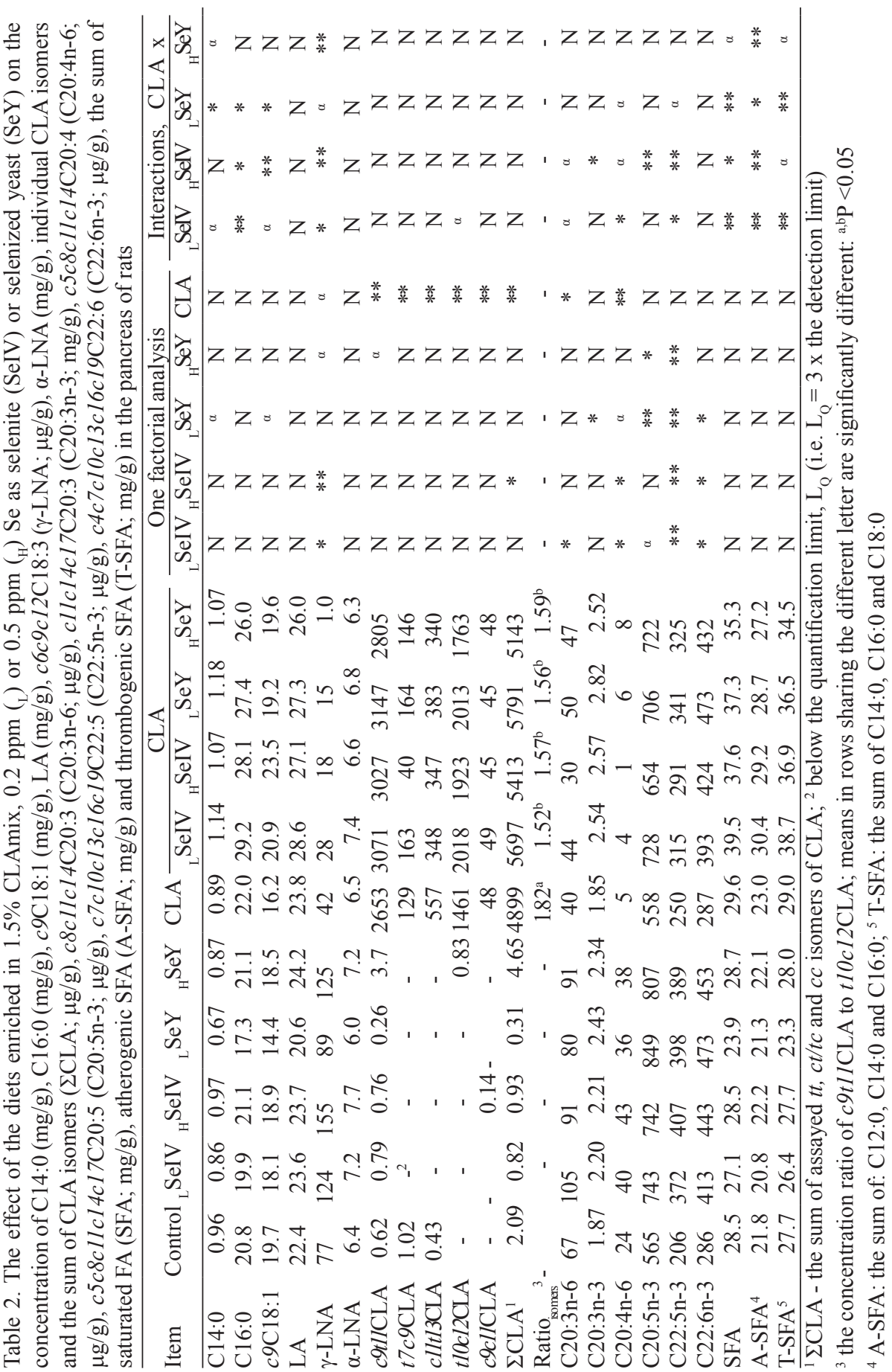


表岕

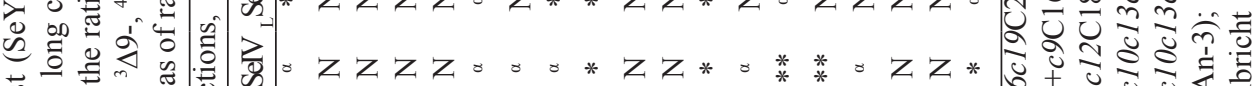

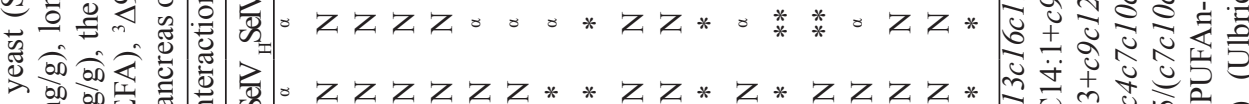

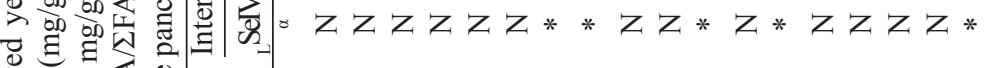

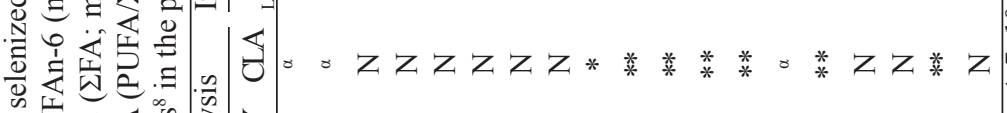

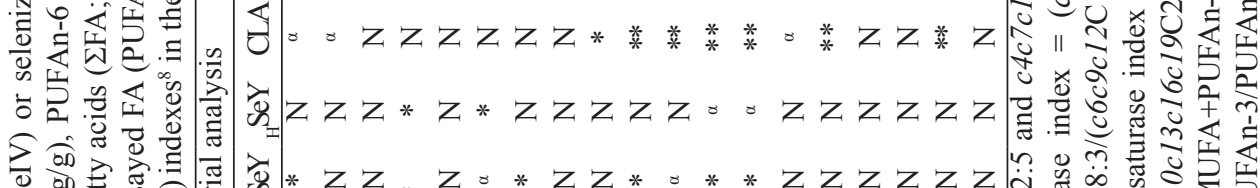

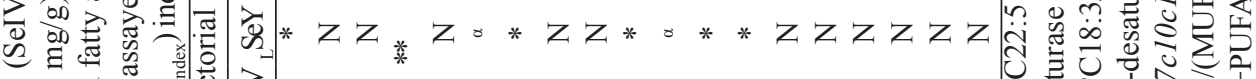
.

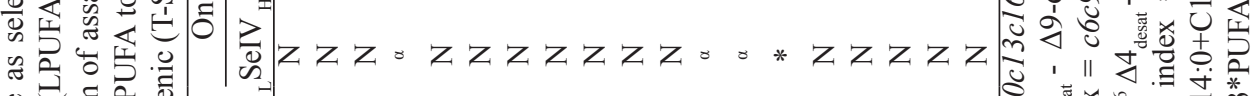

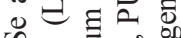
थि के

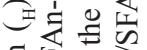

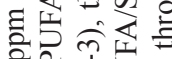
ㄴㄷㅇ ?

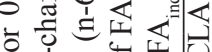
- bo 40 出 Э它主文

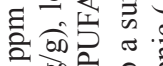
त) 0 낭 氙主完吉 在它充 是宫足焉

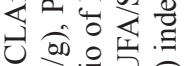
ㅇํㄹㄹㅠ n 4 \& . 死志究 궁ㅇㅇ

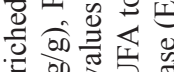

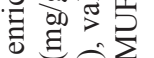
导近 की

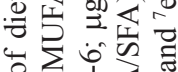
范焉在 进司它

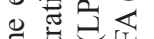
F ri - ठํㄴ

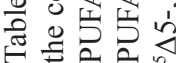

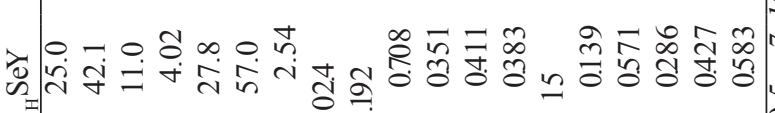

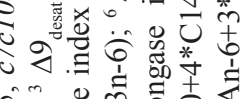

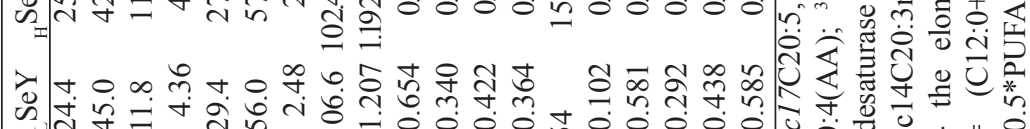

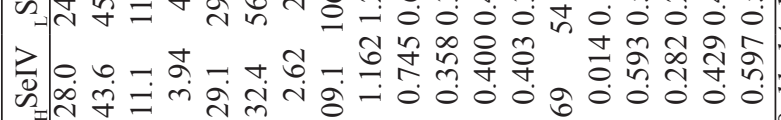
幽舟

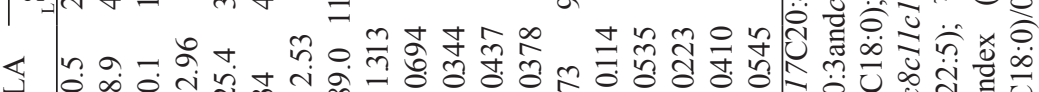
ঊ त̂

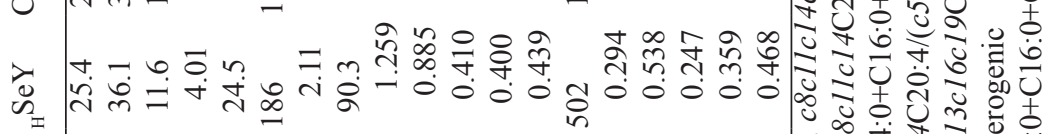

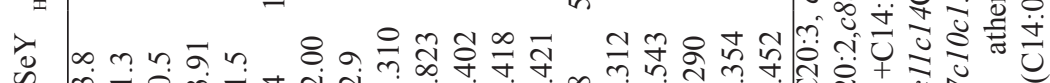

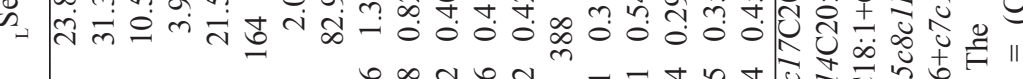

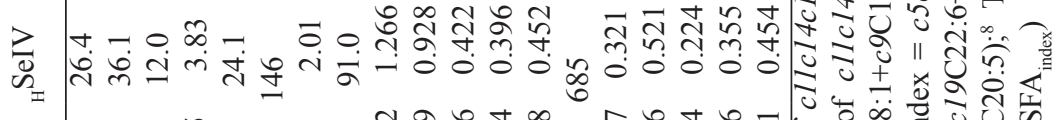

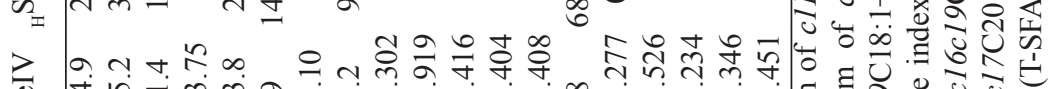

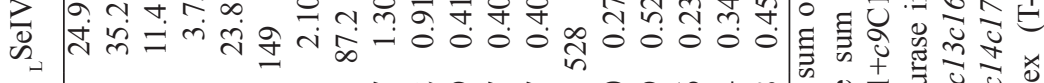

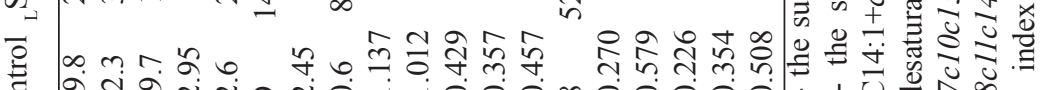
उ तें

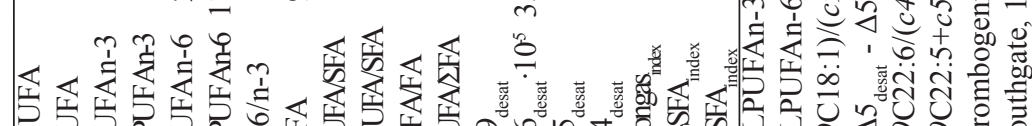

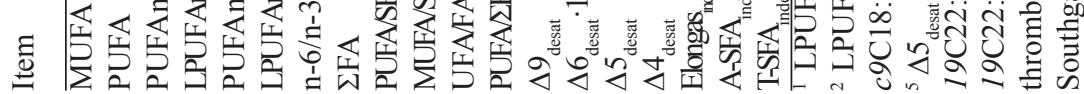


the $\mathrm{R}_{\text {cttIICLA } t \text { I0c } 2 \text { CLA }}$ value in the pancreas of rats fed the containing diet only CLAmix (Table 2). Therefore, it can be hypothesized that dietary SeIV (selenite) or SeY (i.e. organic Se) diminished the efficiency of $\beta$-oxidation of $t 10 c 12 \mathrm{CLA}$ and $t 10 t 12 \mathrm{CLA}$ in the pancreas of rats. Selenate added to rat diets exhibited a similar effect on the $\beta$-oxidation of $t 10 c 12 \mathrm{CLA}$ and t10t12CLA (Niedźwiedzka et al., 2007).

Effect of the diets with CLAmix and Se on pancreatic contents of selected polyunsaturated FA. As expected, the experimental diets enriched in CLAmix and $\mathrm{Se}\left(\right.$ as $_{\mathrm{L}} \mathrm{SeIV},{ }_{\mathrm{H}} \mathrm{SeIV},{ }_{\mathrm{L}} \mathrm{SeY}$ or ${ }_{\mathrm{H}} \mathrm{SeY}$ ) numerically increased the concentration of linoleic acid (LA) in the pancreas in comparison with the control group as well as with rats fed the diets with a single additive (SeIV, SeY, or CLAmix) (Table 2). On the other hand, the diets containing both additives significantly decreased the concentration of $\gamma$-linolenic acids ( $\gamma$-LNA) in the pancreas (the negative interactions) compared with the control group or rats fed the diet containing only extra Se or CLAmix. The increase in the concentration of LA (the substrate) and decrease in the concentration of $\gamma$-LNA (the product) in the pancreas might be related to the decrease in the value of the $\Delta 6$-desaturase index in the pancreas of rats fed the diets containing CLAmix and extra Se (as SeIV or SeY) (Table 3). Indeed, the diets enriched in both additives significantly reduced the capacity of pancreas desaturase in comparison with the control group. Also the diet with CLAmix decreased this desaturase index, while the diets with extra Se as SeIV or $\mathrm{SeY}$ increased the value of the $\Delta 6$-desaturase index compared with the control group. Consequently, the concentration of $\gamma$-LNA in the pancreas changed in good accordance with changes of these values of the $\Delta 6$-desaturase index in the pancreas of rats fed the diet enriched in ${ }_{\mathrm{L}} \mathrm{SeIV},{ }_{\mathrm{H}} \mathrm{SeIV},{ }_{\mathrm{L}} \mathrm{SeY},{ }_{\mathrm{H}} \mathrm{SeY}$ or CLAmix, respectively. A similar effect of the experimental diets was found on the $\Delta 5$ desaturase index in the rat pancreas (Table 3).

The concentration of $c 8 c 11 c 14 \mathrm{C} 20: 3$ (C20:3n-6) and $c 5 c 8 c 11 c 14 \mathrm{C} 20: 4$ $(\mathrm{C} 20: 4 \mathrm{n}-6)$ decreased in the pancreas of rats fed the diets enriched in CLAmix and $\mathrm{Se}$ (as SeIV or SeY) compared with the control rats or rats fed the diets containing only a single additive (Table 2). These differences in the concentrations of C20:3n- 6 and C20:4n-6 are related to differences in the pancreatic concentration of the precursor of these long-chain fatty acids (i.e. $\gamma$-LNA) . Indeed, C20:3n- 6 is the elongation product of $\gamma$-LNA, while C20:4n-6 is the product of elongation and $\Delta 5$-desaturation of $\gamma$-LNA (Belury, 2002; Czauderna et al., 2007a). Our results documented that the concentration of $\gamma$-LNA (the substrate) in the pancreas determined the biosynthesis yield of long-chain polyunsaturated $n-6$ fatty acids (i.e. C20:3n-6 and C20:4n-6 ).

The concentrations of $c 11 c 14 c 17 \mathrm{C} 20: 3$ (C20:3n-3), $c 5 c 8 c 11 c 14 c 17 \mathrm{C} 20: 5$ (C20:5n-3), c7c10c13c16c19C22:5 (C22:5n-3) and $c 4 c 7 c 10 c 13 c 16 c 19 \mathrm{C} 22: 6$ 
(C22:6n-3) increased in the pancreas of rats fed the diets enriched in CLAmix and SeIV or SeY, regardless of the concentration of extra Se (Table 2). Based on findings from a number of laboratories (e.g., Belury et al., 2002), current results and our recent studies (Korniluk et al., 2007), we argue that dietary CLA isomers, especially in the presence of Se as selenite or SeY, reduced desaturase and elongate anabolites of LA (e.g., eicosanoid synthesis from n-6 PUFA precursors), while stimulating the eicosanoid biosynthesis from n-3 PUFA, i.e. the pathway for eicosanoid synthesis from n-3 PUFA precursors. Also the diet enriched in SeIV or SeY, irrespective of the concentration of extra Se, increased the concentration of these long-chain n-3 PUFA, i.e. PUFA n-3-derived eicosanoids. The above findings are in good accordance with changes in the concentration of n-3 LPUFA and n-6LPUFA in the pancreas of rats fed the experimental diets (Table 3). Indeed, the diets enriched in CLAmix and $\mathrm{Se}$ (as SeIV or SeY) increased the concentration of n-3 LPUFA, the sum of fatty acids ( $\Sigma F A$ ), and decreased the content of $n-6$ LPUFA in the pancreas in comparison with the control rats. Similarly, the diets with only SeIV or SeY, regardless of the level of extra Se, increased the concentration of Ln-3 PUFA, the PUFA/SFA and PUFA/ $/ \mathrm{FA}$ ratio, whereas decreased the n-6 PUFA/n-3 PUFA ratio (n-6/n-3) in the pancreas compared with the control group. In addition, other experimental diets increased the PUFA/ $\Sigma F A$ ratio in the pancreas compared with the control rats, although the diet enriched in CLAmix with or without ${ }_{L} \mathrm{SeY}$ most effectively increased the value of the $n-6 / n-3$ ratio in the pancreas. The current results and our recent finding (Czauderna et al., 2004, 2007a, 2009a,b, 2010) documenting that dietary Se and/or CLA isomers fed to animals considerably increase the level of CLA isomers, non-CLA fatty acids containing conjugated double bonds (Ulbricht and Southgate, 1991; Czauderna et al., 2004) and PUFA, especially n-3 PUFA, improving the n-6/n-3 ratio in some internal organs and muscles of animals, is valuable information for nutritionists carrying out research to improve the nutritive value of food for human health.

\section{CONCLUSIONS}

The presented study demonstrated that the rat diet enriched in the CLA isomer mixture, selenite or selenized yeast affected the body weight gain, pancreas mass, feed conversion efficiency, as well as the concentration of fatty acids in the pancreas of rats. The rat diet enriched in CLAmix and HSeIV most effectively stimulated the body weight gain and pancreas mass. In adition, diets containing CLAmix and selenite or selenized yeast (regardless of the concentration of extra Se) increased the concentration of 


\section{PUFA and, more importantly, CLA isomers, PUFAn-3 and LPUFAn-3, as well as improved the PUFAn-6/PUFAn-3 ratio in the pancreas of rats.}

\section{REFERENCES}

Alasnier C., Berdeaux O., Chardigny J.M., Sébédio J.L., 2002. Fatty acid composition and conjugated linoleic acid content of different tissues in rats fed individual conjugated linoleic acid isomers given as triacylglycerols. J. Nutr. Biochem. 13, 337-345

Belury M.A., 2002. Dietary conjugated linoleic acids in health: Physiological effects and mechanisms of action. Annu. Rev. Nutr. 22, 505-531

Boosalis M.G., 2008. The role of selenium in chronic disease. Nutr. Clin. Pract. 23, 152-160

Czauderna M., Kowalczyk J., Wąsowska I., Niedźwiedzka K.M., Pastuszewska B., 2004. Conjugated linoleic acid (CLA) content and fatty acids composition of muscle in rats fed isomers of CLA and selenium. J. Anim. Feed Sci. 13, 183-196

Czauderna M., Kowalczyk J., Korniluk K., 2007a. Effect of dietary conjugated linoleic acid mixture and selenized yeast on concentrations of selected fatty acids and mineral elements in rats. Arch. Anim. Nutr. 61, 135-150

Czauderna M., Kowalczyk J., Korniluk K., Wąsowska I., 2007b. Improved saponification then mild base and acid-catalyzed methylation is a useful method for quantifying fatty acids, with special emphasis on conjugated dienes. Acta Chromatogr. 18, 59-71

Czauderna M., Kowalczyk J., Krajewska K.A., Michalski J.P., 2010. The dietary level of selenite and selenized yeast influences the concentrations of selected fatty acids in the abdominal fat and brain of rats. J. Anim. Feed. Sci. 19, 113-129

Czauderna M., Kowalczyk J., Krajewska K.A., Rozbicka A.J., Michalski J., 2009a. Dietary selenite and conjugated linoleic acid isomers influence fatty acid concentrations in the liver and femoral muscles of rats. J. Anim. Feed Sci. 18, 564-581

Czauderna M., Kowalczyk J., Niedźwiedzka K.M., Leng L., Cobanova K., 2009b. Dietary selenized yeast and CLA isomer mixture affect fatty- and amino acid concentrations in the femoral muscles and liver of rats. J. Anim. Feed Sci. 18, 348-361

Han F., Chen D., Yu B., Wenli L., 2009. Effects of different selenium sources and levels on serum biochemical parameters and tissue selenium retention in rats. Front. Agr. China 3(2), 221-225

Javadi M., Geelen M.J.H., Everts H., Lemmens A.G., Beynen A.C., 2007. Body composition and selected blood parameters in mice fed a combination of fibre and conjugated linoleic acid. J. Anim. Physiol. Anim. Nutr. 91, 492-497

Juniper D.T., Phipps R.H., Ramos-Morales E., Bertin G., 2008. Effect of dietary supplementation with selenium-enriched yeast or sodium selenite on selenium tissue distribution and meat quality in beef cattle. J. Anim. Sci. 86, 3100-3109

Korniluk K., Czauderna M., Kowalczyk J., 2007. The influence of dietary conjugated linoleic acid isomers and high- selenized yeast on the fatty acid profile of spleen, pancreas and kidneys of rats. J. Anim. Feed Sci. 16, 121- 139

Navarro-Alarcon M., Cabrera-Vique C., 2008. Selenium in food and the human body: A review. Sci. Total Envir. 400, 115-141

Niedźwiedzka K.M., Korniluk K., Kowalczyk J., Czauderna M., 2007. Influence of dietary CLA isomers and selenium compounds on the fatty acid and amino acid profiles in blood plasma of rats. J. Anim. Feed Sci. 16, 257-273

Rayman M.P., 2004. The use of high-selenium yeast to raise selenium status: How does it measure up? Brit. J. Nutr. 92, 557-573 
Suzuki K.T., 2005. Metabolomics of selenium: Se metabolites based on speciation studies. J. Health Sci. $51,107-14$

Tapiero H., Townsend D.M., Tew K.D., 2003. The antioxidant role of selenium and selenocompounds. Biomed. Pharmacotherapy 57, 134-144

Ulbricht T.L.V., Southgate D.A.T., 1991. Coronary heart disease: seven dietary factors. Lancet 338, 985-992

Weiss W.P., Hogan J.S., 2005. Effect of selenium source on selenium status, neutrophil function, and response to intra-mammary endotoxin challenge of dairy cows. J. Dairy Sci. 88, 4366-4374

Whanger P.D., 2004. Selenium and its relationship to cancer: an update. Brit. J. Nutr. 91, 11-28

Yu L.L., Wang R.L., Zhang Y.Z., Kleemann D.O., Zhu X.P., Jia Z.H., 2008. Effects of selenium supplementation on polyunsaturated fatty acid concentrations and anti-oxidant status in plasma and liver of lambs fed linseed oil or sunflower oil diets. Anim. Feed Sci. Tech. 140, 39-51 